\title{
ADOLESCER E ADOECER NA PERSPECTIVA DE JOVEM E FAMÍLIA
}

\author{
TO BE AN ADOLESCENT AND SICKEN IN THE YOUTH'S \\ AND FAMILY'S PERSPECTIVE
}

\section{SER UN ADOLESCENTE ENFERMO EN LA PERSPECTIVA DEL JOVEN Y DE LA FAMILIA}

\author{
ÍtAla PARIS De SouzA* \\ Roseney BeLlato ${ }^{* *}$ \\ Laura Filomena Santos de Araújo ${ }^{* * *}$ \\ Karla Beatriz Barros de Almeida ${ }^{* * *}$
}

\begin{abstract}
RESUMO
Objetivo: Este estudo busca enfatizar a vivência do adolescer concomitante ao adoecer através de linha de adoecimento e desenvolvimento de jovem que, na adolescência, experienciou a instauração de condição crônica por agravos concomitantes -doença renal e câncer. Método: Pesquisa de abordagem compreensiva, modelado como estudo de situação, através da História de Vida, operacionalizada por Entrevista em Profundidade e observação de campo; sendo sujeitos do estudo um jovem adoecido e alguns membros de sua família. Resultados: $\mathrm{O}$ desenho de linhas imbricadas do adoecimento e do adolescer possibilitou compreender as diferentes fases da condição crônica por agravos concomitantes e suas significativas repercussões para a vida do jovem. Dessa imbricação entre o adolescer e o adoecer, emergiram diversos enfrentamentos mediante as modificações físicobiológicas, comportamentais e sociais vivenciadas, configurando essa experiência única e complexa. Conclusão: Tal compreensão se mostra importante aos profissionais de saúde, de modo que busquem atender as necessidades do ser humano em desenvolvimento como um todo, não apenas as manifestações da doença.
\end{abstract}

Palavras chave: Neoplasias, adolescente, família, enfermagem.

\begin{abstract}
Objective: This study seeks to highlight the experience of being an adolescent and concomitantly suffer a chronic condition. The study focuses on a teenager who experienced the establishment of a chronic condition due to concomitant aggravations -kidney disease and cancer during adolescence. Methodology: A comprehensive study modeled as a situational analysis of Life History was performed by means of in-depth interviews and field observations. The test subjects were a teenager suffering from a chronic disease and some of his family members. Results: By intertwining the realities of suffering a chronic condition and going through adolescence,

\footnotetext{
* Enfermeira. Mestranda em Enfermagem. UFMT, Programa de Pós Graduação, GPESC. Cuiabá, MT - Brasil. E-mail: italaparis@hotmail.com

** Enfermeira. Doutora em Enfermagem. Professora. UFMT/FAEN, GPESC. Cuiabá, MT - Brasil. E-mail: roseneybellato@ gmail.com

${ }_{* * \star}$ Enfermeira. Doutora em Enfermagem. Professora. UFMT, Faculdade de Enfermagem - FAEN. Líder do GPESC. Cuiabá, MT - Brasil. E-mail: laurafil1@yahoo.com.br.

${ }_{* * * *}$ Enfermeira. Mestre em Enfermagem pelo Programa de Pós-Graduação em Enfermagem da FAEN/UFMT. Cuiabá, MT, Brasil.E-mail: karlinha_bba@hotmail.com
} 
we were able to understand the different stages of said chronic condition due to concomitant aggravations and its significant impact on the life of the teenager. Several conflicts emerged from this overlap of adolescence and disease due to physical, biological, behavioral, and social changes; which make such experience complex and unique. Conclusion: This understanding proves important to health professionals allowing them to holistically meet the needs of a developing human being and not only pay attention to the manifestations of the disease.

Key words: Neoplasia, adolescents, family, nursing.

\section{RESUMEN}

Objetivo: En este estudio se pretende dar a conocer la experiencia de ser un adolescente concomitante de caer enfermo a través de la línea de enfermedad y desarrollo del joven, que en la adolescencia ha experimentado el establecimiento de una condición crónica con enfermedades concomitantes: dolencia renal y cáncer. Método: Investigación con enfoque integral modelado como estudio de situación mediante la Historia de Vida, realizada por la Entrevista en Profundidad y observación de campo; el sujeto de estudio fue un joven enfermo y algunos miembros de su familia. Resultados: El diseño de líneas entrelazadas de la enfermedad y del adolescente ha permitido entender las diferentes etapas de la condición crónica resultante de las enfermedades concomitantes y su impacto significativo en la vida de los jóvenes. De este entrelazamiento entre el adolescente y la enfermedad surgieron varios enfrentamientos por los cambios físicos y biológicos, ajuste conductual y social, vividos en esta experiencia compleja y única. Conclusión: Tal entendimiento es importante para los profesionales de la salud, permitiéndoles satisfacer las necesidades del ser humano en desarrollo en su conjunto, y no sólo las manifestaciones de la enfermedad.

Palabras clave: Neoplasias, adolescentes, familia, enfermería.

Fecha recepción: 04/03/15 Fecha aceptación: 08/09/16

\section{INTRODUÇÃO}

A infância é a fase da vida que traz como característica marcante o desenvolvimento físico, neuropsicomotor, psicossocial, psicossexual e cognitivo, o que reflete, por sua vez, significativas mudanças comportamentais (1). Tal desenvolvimento abarca forte influência hereditária e ambiental que perpassa diferentes processos, provocando aumento da capacidade do ser humano de realizar funções cada vez mais complexas (1).

É esperado que a criança se desenvolva dentro de certos padrões de normalidade; entretanto, na vivência de um adoecimento, particularmente o agravo crônico, seu comportamento pode se modificar, expressando sentimentos de medo, culpa, angustia, apatia e ameaça à sua rotina diária. Tais modificações são decorrentes, dentre outros, das limitações de atividades físicas, frequentes hospitalizações, separações do convívio de seus familiares e ambiente doméstico (2).

Também o adolescente, inserido na unidade familiar, vivencia as peculiaridades próprias desta fase da vida e desenvolve diversos enfrentamentos mediante as modificações biológicas, comportamentais e sociais que configuram o adolescer, como experiência única e complexa. Destarte, a transição entre a infância e o estabelecimento da identidade adulta se constitui num dos períodos de maior complexidade do desenvolvimento humano $(3,4)$.

A adolescência se caracteriza por ser uma fase em que a saúde, o bem estar e a vida estão fortemente engajados (5), o que impede 
os adolescentes, em sua maioria, de associar juventude a adoecimento e hospitalização, visto que, de modo geral, são relativamente saudáveis. Porém, por ser considerada um período psicologicamente complexo, alguns fatores característicos parecem ser acentuados e até agravados quando associados ao adoecimento (1).

Dentre os modos de adoecer, ressaltamos aquele que se constitui em situação crônica, visto sua permanência por tempo mais ou menos prolongado e a exigência de cuidados contínuos; e, ainda, tal situação requer compreendermos o contexto de vida e os circuitos de vulnerabilidades (6) em que se inserem a pessoa adoecida e sua família.

É no bojo da situação crônica que buscamos compreender os afetamentos produzidos no viver da pessoa adoecida, particularmente mais intensos por se tratar de uma criança-adolescente, cujo adoecimento 'transversou' o período de sua formação -física, psicológica e social. Assim, o que pretendemos mostrar é a maneira intrincada do adoecer se dar em concomitância com o adolescer.

Para compreender o adoecimento crônico na adolescência é importante apreender as características singulares do modo próprio de vida do adolescente, já que o adoecimento pode se constituir numa experiência difícil e complexa, podendo deixá-lo, então, fragilizado (7). Ademais, a maneira como acontecerá o enfrentamento do adoecer tem relação com a magnitude da doença quanto ao processo patológico em si e as limitações que impõe ao viver do adolescente, como a diminuição ou interrupção de atividades físicas e aquelas que compõem sua vida cotidiana e escolar, afetando-lhe, sobremaneira, os projetos futuros. Essa experiência é, ainda, influenciada pela capacidade de o adolescente e sua família lidarem com a situação, dentre outros aspectos (8).

Mediante os inúmeros afetamentos que o adoecimento crônico produz na vida do adolescente e de sua família, trazendo necessidades ampliadas de cuidado e impondo a garantia do substrato essencial para que esse cuidado aconteça de modo continuado e prolongado, assumimos que essa vivência, pessoal e familiar ao mesmo tempo, constitui-se em uma "situação crônica de adoecimento" (9). No bojo dessa situação, apreendemos a família como unidade cuidadora indispensável, que se reorganiza no propósito de empreender esforços na busca, produção e gerenciamento do cuidado cotidiano exigido pelo adolescente adoecido (10).

Assim, neste estudo busca enfatizar a vivência do adolescer e adoecer é apresentada por meio de linha de adoecimento e desenvolvimento de jovem que, na adolescência, experienciou a instauração de condição crônica por agravos concomitantes -doença renal e câncer.

O caráter inovador do estudo se faz em relevar o cuidado centrado na pessoa, como aponta a Organização Mundial de Saúde, priorizando as dimensões humanas em saúde na complexidade do viver (11). Tal complexidade está "associada à necessidade de garantir uma abordagem holística que considere aspectos físicos, emocionais e sociais, o passado e o futuro de cada um e as realidades do contexto em que cada indivíduo vive" (11).

Para a produção de práticas em saúde mais efetivas e duradouras, faz-se importante que os profissionais de saúde se aproximem da experiência de vida de cada pessoa cuidada, a fim de melhor acolher suas necessidades. Assim, este estudo, pela descrição minuciosa que faz, permite conhecer a imbricação das diferentes fases da adolescência com a instauração do adoecimento, experienciado de forma peculiar pelo jovem e sua família; permite ainda destacar o esforço da família que empreendeu árdua busca por cuidados requeridos pelo jovem. Desse modo, possibilita aos profissionais de saúde compreender como o adolescente em adoecimento percebe, vive e reage diante dos muitos afetamentos em sua vida, dando-lhes subsídios para conceberem práticas que busquem respon- 
der às necessidades do ser humano em desenvolvimento como um todo, e não apenas as manifestações da doença.

\section{MÉTODO}

Guiamo-nos pela abordagem compreensiva, pois permite apreender, de forma mais alargada, as experiências vividas pelas pessoas, suas relações e percepções, bem como os contextos peculiares do cotidiano em família. Dessa forma, centramo-nos na apresentação do "como as coisas passam e se passam, em descrição minuciosa das situações vivenciadas pelas pessoas" (12).

Em consonância com tal abordagem, foi realizado um "estudo de situação", por nos possibilitar perceber a situação e contexto peculiares de vida dos participantes do estudo, principalmente ao longo do período de adoecimento e cuidado (9).

O corpus de análise foi composto por meio da História de Vida (HV), operacionalizada pela Entrevista em Profundidade (EP) (13), realizada através de diversos encontros com um jovem de 21 anos, Marco, e alguns membros de sua família -seu pai Olavo, sua mãe Rita e sua tia Lair-, referências importantes para o jovem, segundo ele próprio. A entrevista, do tipo aberta, foi conduzida como uma conversa interessada, guiada pela questão norteadora "conte-nos como tem sido a sua experiência de adoecimento e busca por cuidados". Assim, indagações foram realizadas, conforme o desenvolvimento da rememoração do vivido pelos entrevistados, com aprofundamento paulatino dos fios narrativos (13) que se mostravam de maior interesse para o estudo.

Foram realizados onze encontros de entrevista de março a maio de 2011 em Cuiabá-MT, onde mora a família da tia Lair; em Cidade A, onde residiu Marco com sua família; e em Cidade B, onde Marco residia com irmãos e primo. A entrevista com gravação de voz foi acompanhada pela observação de campo e pelo registro de filmagem e fotografia. Este material foi organizado no Diário de Pesquisa, composto por 212 páginas digitadas, e consistiu em nosso corpus de análise.

A leitura atenta e intensiva do corpus nos direcionou ao objetivo proposto, ou seja, enfatizamos nas narrativas, em realces coloridos, os elementos que apontassem para a vivência do adolescer em concomitância ao adoecer. A partir desses realces, ordenamos, cronologicamente, as narrativas e os eventos no curso da vida do jovem, desenhando uma linha que demarcava as fases do seu desenvolvimento e do seu adoecimento ${ }^{1}$. Enfatizamos, então, em cores diversas, o período da adolescência em que o agravo renal que o afetava desde a tenra infância segue em concomitância com a instauração do câncer linfático não Hodgkin a partir dos 14 anos. Posteriormente, realizamos a ordenação das narrativas, segundo os sentidos inicialmente apreendidos.

A releitura desse ordenamento nos possibilitou construir um quadro descritivo-analítico do adoecimento e desenvolvimento (Figura 1). Nele expusemos, em colunas enumeradas de um a quatro, a escansão temporal dos acontecimentos expressa em idade do jovem e ano do ocorrido. Expusemos, então, em linhas, os eventos relevantes destas vivências, sendo elas: $1^{\text {a }}$. Linha Temporal do adoecer por câncer e problema renal, evidenciando sua sequência e/ou concomitância na vida de Marco; 2a. Progressão do Adoecimento (A) e as intervenções médicas a que Marco foi submetido; $3^{a}$. Ciclo da Vida (CV) e, nele, os afetamentos do adoecer para Marco e sua família. Uma última linha evidencia, segundo preconizado pelo Ministério da

${ }^{1} \mathrm{O}$ desenho do quadro descritivo analítico do presente estudo foi inspirado a partir de estudo realizado no âmbito do Grupo de Pesquisa, pela autora: Silva AHR. Repercussões da condição crônica por demência senil na vida de uma idosa e de sua família. Relatório de Iniciação Cientifica, Cuiabá: Faculdade de Enfermagem da Universidade Federal de Mato Grosso; 2009. 
Saúde (8), o Desenvolvimento (D) nas fases da vida infantil e adolescente. Para detalhar os eventos contidos em cada linha, foram usadas letras do alfabeto sobrescritas.

Este estudo respeitou as prerrogativas éticas em pesquisa com seres humanos previstos na Resolução 196/96 do Conselho Nacional de Saúde brasileiro, vigente à época da realização do estudo, e encontra-se em consonância com a atual Resolução no 466/12. Assim, o projeto matricial ao qual este estudo se vincula foi aprovado pelo Comitê de Ética em Pesquisa do Hospital Universitário Julio Muller, sob o no 671/CEP-HUJM/09. O jovem e sua família foram esclarecidos sobre os procedimentos da pesquisa com garantia de seu anonimato, reforçado pelo emprego de nomes fictícios para os participantes do estudo.

\section{RESULTADOS}

Para compreendermos os afetamentos decorrentes da concomitância do agravo renal e câncer na vida de Marco e sua família, foi relevante nos aproximar de seu modo de vida desde o nascimento, com descrição minuciosa dos acontecimentos.

Marco, rapaz de 21 anos de idade à época da realização deste estudo, é filho de Rita e Olavo e irmão de três meninas e um rapaz. É adoecido crônico por doença renal desde tenra infância e por câncer desde a adolescência. Residiu em pequena propriedade rural situada na Cidade A, a $210 \mathrm{~km}$ de Cuiabá, MT, durante toda sua infância e adolescência. A irmã mais velha e adotiva de Marco, Helena, tem papel relevante no cuidado familiar a Marco. Também Fábio, filho mais velho, Kátia e Keila, irmã caçula de Marco, ajudaramno com orações e palavras de incentivo no enfrentamento do seu adoecimento.

Tia Lair esteve também muito presente nos relatos da família, pois sempre apoiou Marco no processo de busca aos serviços de saúde em Cuiabá. Tios, primos, avós paternos e padrinhos do jovem contribuíram no seu cuidado durante o adoecimento; por morarem em casas próximas na mesma propriedade rural, o convívio se mostrou facilitado. Ainda, a comunidade rural à que a família pertence contribuiu com ajuda financeira, dentre outras, para custear o seu tratamento. Na Figura 1 representamos o desenvolvimento de Marco e as repercussões trazidas pelo adoecimento crônico por agravos concomitantes, como elemento importante na compreensão dessa vivência pessoal e em família.

As primeiras manifestações do adoecimento na vida de Marco ocorreram logo após o seu nascimento, com episódios de edema de face e de membros e dores em região lombar (Fig.1, 1A $\mathrm{A}^{\mathrm{a}}$ ). Aos três anos de idade, seu pai o levou à Cuiabá para consulta médica; porém, a profissional afirmou que não havia com o que se preocupar, pois as dores decorriam de um processo fisiológico normal que se resolveria espontaneamente (Fig.1, $1 \mathrm{~A}^{\mathrm{b}}$ ).

Nesse período, os pais de Marco eram os responsáveis pela busca por cuidados para amenizar seu sofrimento (Fig.1, 1CV). Tal busca tornou-se constante, tendo a família que se mobilizar intensamente à procura de cuidados em cidades vizinhas e na capital do Estado:

Direto!... Era uma vez por mês, duas vezes né... [...] Aí tava levando, com essa frequência... (Olavo).

Conforme relatado de modo enfático pelos pais, Marco, desde o nascimento, apresentava choro constante devido às dores intensas ocasionadas pelo 'problema no rim'; com o tempo, passou a ser associado a outros sintomas (Fig.1, 1A $\mathrm{A}^{\mathrm{a}}$ ). Essa agonia constante compeliu seus pais a procurarem atendimento médico na Cidade A (Fig.1, 1 ${ }^{\mathrm{b}}$ ), que não foi resolutivo. Conforme aprendia a se comunicar, o menino apontava o local doloroso, na região lombar (Fig.1, 1A $\mathrm{A}^{\mathrm{a}}$ ).

As buscas por serviços de saúde se mantiveram por seis anos, sem resolução para o so- 
Figura 1. Adoecimento e desenvolvimento de jovem e família que vivenciam adoecimento crônico concomitante: câncer e doença renal, 2012.

\begin{tabular}{|c|c|c|c|}
\hline $\begin{array}{c}\text { Coluna } 1 \\
\text { De } 1989 \text { à } 1992 \\
(0-3 \text { anos })\end{array}$ & $\begin{array}{c}\text { Coluna } 2 \\
\text { De } 1992 \text { à } 1998 \\
(4-9 \text { anos })\end{array}$ & $\begin{array}{c}\text { Coluna } 3 \\
\text { De } 1998 \text { à } 2006 \\
(10-17 \text { anos })\end{array}$ & $\begin{array}{c}\text { Coluna } 4 \\
\text { De } 2006 \text { à } 2011 \\
(18-21 \text { anos })\end{array}$ \\
\hline Linha Temporal & & $\square \square \square \square \square \square \square \square \square$ & $\square$ \\
\hline $\begin{array}{l}\text { Adoecimento (A) } \\
\text { - Início das dores renais - } \\
\text { Choros apontando região } \\
\text { lombar; } \mathbf{1 A}^{\mathrm{a}} \\
\\
\text { - Em Cuiabá a médica refere } \\
\text { que as dores tratavam-se } \\
\text { de um processo fisiológico } \\
\text { normal que se resolveria } \\
\text { espontaneamente; } \mathbf{1 A}^{\mathbf{b}}\end{array}$ & $\begin{array}{l}\text { - Continuidade das dores } \\
\text { renais e busca por serviços } \\
\text { em saúde; } \mathbf{2 A}^{\mathrm{a}} \\
\text { - Primeira cirurgia: corre- } \\
\text { ção de estenose de ureter } \\
\text { - Permanece } 22 \text { dias inter- } \\
\text { nado; } 2 \mathbf{A}^{\mathrm{b}}\end{array}$ & $\begin{array}{l}\text { - } 13 \text { anos: relato de dores no } \\
\text { ouvido direito; } 3 \mathbf{A}^{\mathrm{a}} \\
\text { - Diagnóstico Linfoma: } \\
\text { tratamento quimioterápico: } \\
8 \text { ciclos; } 3 \mathbf{A}^{\mathrm{b}} \\
\text { - } 14 \text { anos: segunda cirurgia } \\
\text { renal e logo após início da } \\
\text { quimioterapia; } 3 \mathrm{~A}^{\mathrm{c}} \\
\text { - Passado } 1 \text { ano e } 8 \text { meses: } \\
\text { recidiva tumoral; } 3 \mathbf{A}^{\mathrm{d}} \\
\text { - Medicamento recomenda- } \\
\text { do, Rituximab, não forneci- } \\
\text { do pelo SUS; } \mathbf{3 A ^ { \mathrm { e } }}\end{array}$ & $\begin{array}{l}\text { - } 20 \text { anos: realiza tratamen- } \\
\text { to oncológico para adultos } \\
\text { para continuidade dos cui- } \\
\text { dados; } 4 \mathbf{A}^{\mathrm{a}} \\
\text { - Pouca remissão do tumor; } \\
\mathbf{4 \mathbf { A } ^ { \mathrm { b } }} \\
\text { - Realiza tratamento radio- } \\
\text { terápico de julho à agosto } \\
\text { de } 2010 ; \mathbf{4 A ^ { \mathrm { c } }} \\
\text { - } 21 \text { anos: acompanhamen- } \\
\text { to oncológico } 4 \mathrm{~A}^{\mathrm{d}} \text { e uso } \\
\text { de citrato de potássio para } \\
\text { litíase renal; } 4 \mathbf{A}^{\mathrm{e}}\end{array}$ \\
\hline $\begin{array}{l}\text { Ciclo de vida }(\mathrm{CV}) \\
\text { - Marco morava com os } \\
\text { pais, que viviam em função } \\
\text { do filho para amenizar o } \\
\text { sofrimento; } 1 \mathrm{CV}\end{array}$ & $\begin{array}{l}\text { - Evento estressor mediante } \\
\text { cirurgia; } 2 \mathbf{C V}^{\mathbf{a}} \\
\text { - Brincava com os amigos } \\
\text { da comunidade; } 2 \mathbf{C V}^{\mathrm{b}}\end{array}$ & 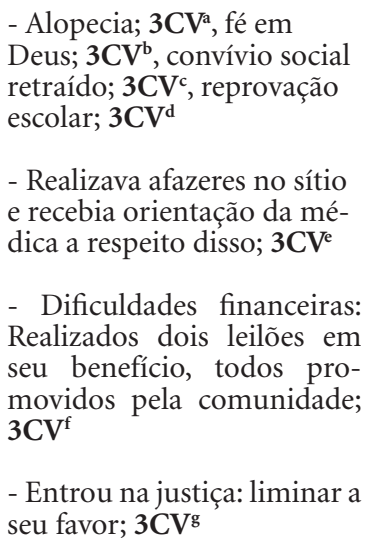 & $\begin{array}{l}\text { - Efeitos colaterais do trata- } \\
\text { mento radioterápico; } 4 \mathbf{C V}^{\mathbf{a}} \\
\text { - Forte apoio da tia Lair; } \\
\mathbf{4} \mathbf{C V}^{\mathrm{b}} \\
\text { - Marco passou a morar na } \\
\text { cidade B; } 4 \mathbf{C V}^{\mathrm{c}} \\
\text { - O jovem namora e planeja } \\
\text { casar, estudar, ter um em- } \\
\text { prego, casar e constituir uma } \\
\text { família; } 4 \mathbf{C V}^{\mathrm{d}}\end{array}$ \\
\hline $\begin{array}{l}\text { Desenvolvimento (D) } \\
\text { - Primeiro sorriso, primeira } \\
\text { palavra, primeiros passos, } \\
\text { primeiro alcançar de um } \\
\text { objeto; } \text { 1D }^{\mathrm{a}} \\
\text { - Elaboração simbólica: co- } \\
\text { meça pelo choro, que a mãe } \\
\text { atende como demanda. 1D } \\
\\
\text { - Da mostra de prazer (sor- } \\
\text { rir) e desconforto (choro); } \\
\text { 1D }^{\mathrm{c}}\end{array}$ & $\begin{array}{l}\text { - Idade do brincar e do ex- } \\
\text { plorar; } 2 D^{\mathbf{a}} \\
\text { - A criança começa a viven- } \\
\text { ciar sentimentos de ambiva- } \\
\text { lência em relação aos mais } \\
\text { próximos: o pai e a mãe. Ao } \\
\text { menor sinal de proibição, faz } \\
\text { birras, chora e fica cheio de } \\
\text { vontades; } 2 D^{\mathbf{b}} \\
\text { - Expressa suas ideias, conta } \\
\text { histórias; } \\
\text { - Começa a dar grandes } \\
\text { passos para a independên- } \\
\text { cia; } 2 D^{\mathrm{c}}\end{array}$ & $\begin{array}{l}\text { - Busca por identidade sexu- } \\
\text { al, familiar e laboral; 3D } \\
\text { - Busca de si mesmo e de sua } \\
\text { identidade; separação pro- } \\
\text { gressiva dos pais; tendência } \\
\text { grupal; necessidade de inte- } \\
\text { lectualizar e fantasiar; crises } \\
\text { religiosas; 3D } \\
\text { Transformações no corpo; } \\
\text { 3D }^{\mathbf{c}}\end{array}$ & $\begin{array}{l}\text { - Anseia por autonomia; } \\
\text { toma decisões sobre a sua } \\
\text { saúde e sua vida; } 4 \mathrm{D}^{\mathrm{a}} \\
\\
\text { - Preocupação com o início } \\
\text { do relacionamento amoro- } \\
\text { so; } 4 \mathrm{D}^{\mathrm{b}} \\
\text { - Preocupação com o futuro } \\
\text { e com a vida profissional: } \\
\text { começa a projetar sua vida; } \\
\text { DD }^{\mathrm{c}}\end{array}$ \\
\hline
\end{tabular}

Legenda:

Doença Renal fase estável

Doença Renal fase aguda

- - Linfoma fase aguda

- Linfoma fase estável 
frimento de Marco. Aos nove anos, passou a relatar a intensificação das dores, o que levou seu pai a procurar atendimento de urgência

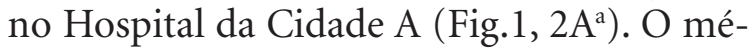
dico que os atendeu solicitou ultrassom de abdome e, só então, foi diagnosticada hidronefrose do rim esquerdo decorrente de estenose de ureter. A criança foi encaminhada para tratamento em Hospital Filantrópico de Cuiabá, onde ocorreu sua primeira cirurgia para correção da estenose (Fig. 1, 2A ${ }^{\mathrm{b}}$ ).

Marco e sua família relataram que esse foi um período de grande sofrimento (Fig.1, $\left.2 \mathrm{CV}^{\mathrm{a}}\right)$ :

Ele ficou usando, como que fala, aquele dreno lá, que drena [...] (Rita). Da primeira, [referindo à primeira cirurgia renal] deu muito pobrema. Daí tava vazando direto... Não sei se é que o líquido não queria vazar e doía [...] (Marco). É, deu quarenta grau de febre uma vez lá no Hospital Filantrópico (Olavo).

A partir de então, Marco precisou se submeter a frequentes exames e cirurgias. E se, por um lado, considerávamos tratar-se de um momento difícil para uma criança, todavia, sua família relatou-nos que situação diversa ocorreu com ele:

No tempo que ele era criança [...] pra ele foi ótimo, né, que ele não tinha de jeito nenhum pobrema, não tinha tristeza, não tinha essa choradeira, não tinha nada. [...] (Helena).

Mesmo durante o adoecimento, especificamente no período de convalescença da cirurgia renal, Marco era uma criança alegre e animava-se em brincar com os amigos da comunidade rural em que residia (Fig. 1, 2CV $\mathrm{CV}^{\mathrm{b}}$ ).

Ainda em vigência do acometimento renal, Marco foi afetado novamente por acontecimento marcante e estressor: a instauração do câncer, sinergizando-se com o início de sua adolescência (Fig.1, 3A $\mathrm{A}^{\mathrm{c}}$ ).

Aos treze anos, relatou dores no ouvido direito (Fig. 1, 3A $\mathrm{A}^{\mathrm{a}}$, sendo diagnosticado lin- foma em maxilar direito (Fig.1, 3A $\mathrm{A}^{\mathrm{b}}$ ). Porém, para iniciar o tratamento quimioterápico, havia a necessidade de tratar a doença renal preexistente e persistente. Marco, então, foi submetido à segunda cirurgia para correção do ureter esquerdo, permanecendo sete dias internado (Fig. 1, 3A $\mathrm{A}^{\mathrm{c}}$ ).

Nos relatos do jovem e de seu pai, podemos observar o modo abrupto como ocorreram tais acontecimentos (Fig.1, 3A $\mathrm{A}^{\mathrm{c}}$ ):

É porque fez [a cirurgia], de lá você já saiu à noite pro hospital de oncologia... Aí já saiu, foi pro hospital do câncer [...] É... nem os ponto tirou, eu saí. eu fui lá pro... hospital de oncologia nem os ponto num tiraram...(Olavo).

Eu de lá eu já fui pro hospital de oncologia direto (Marco).

A instauração do agravo câncer em concomitância com o acometimento renal durante sua adolescência não foi entendido por Marco em sua gravidade e consequências:

[...] no começo, assim, que eu recebi que eu tinha esse problema [o câncer] eu, pra mim, nem eu sei [...] eu tinha era 14 anos, [...] aí eu pra mim aquele era... simples né, não era problema [...] sei lá eu acho que não entendia muito bem, né, aí pra mim aquele ali era normal... (Marco).

O câncer apenas passou a ser percebido como algo traumático quando iniciou tratamento quimioterápico:

[...] eu tomei a quimio, tomava ela e aí eu sentia mal, né, porque vomitava, não dava pra comer (Marco).

O jovem relatou que, dentre os efeitos colaterais da quimioterapia, a alopecia foi o mais marcante (Fig.1, 3CV $)$ :

[...] [a enfermeira] falou que o cabelo caía [...] aí eu falei vixi Maria! Aí foi a parte mais ruim né! (Marco). 
Em meio ao inesperado, o processo de adoecer demandou, ainda, a busca por cuidados à saúde, momento em que Marco e sua família tiveram que enfrentar a falta de recursos financeiros e a carência de atendimento adequado por parte dos serviços de saúde, dificultando o cuidado à sua saúde (Fig.1, $3 \mathrm{CV}^{\mathrm{f}}$ ) e o "lidar com" o adoecimento.

Porém, mesmo neste contexto de pouca efetividade dos serviços de saúde, o jovem sempre pode contar com a ajuda de seus familiares no seu cuidado, dentre os quais destacamos tia Lair, que o apoiava nas estadas em Cuiabá para acompanhamento profissional. Ela cedia sua casa todas as vezes que precisava, facilitando o processo de busca aos serviços de saúde (Fig. 1, 4CV ${ }^{\mathrm{b}}$ ). A disposição da tia Lair em ajudar Marco no processo de busca por cuidado mostrou-se muito importante no compartilhar das ações empreendidas pelos familiares em prol de sua recuperação.

Além da ajuda de familiares, os amigos da comunidade rural a que pertenciam apoiaram fortemente o adolescente e sua família, mobilizados pelo adoecimento de Marco e cientes dos gastos advindos do tratamento (Fig.1, 3CV $\mathrm{CV}^{\mathrm{f}}$. Marco nos relatou que a comunidade, incluindo igreja, amigos da vila, diretor e professores da escola e a vizinhança, organizaram dois leilões a fim de arrecadar verbas para ajudar nos custos com o seu tratamento.

Tive uma ajuda né, uma ajuda muito grande (Olavo) [...] É, reuniu a comunidade, os $f a-$ zendeiro. A família, com a comunidade, todo mundo [...] Depois... Resolveram fazer um leilão também. Os professor, aluno... deu em torno de... Onze mil, né deu dez mil... foi uma ajuda muito grande! (Rita).

Esse apoio recebido por Marco, tanto por parte dos familiares como da comunidade, foi de grande valia para suprir suas necessidades com o tratamento.

Em meio ao apoio da família e da co- munidade, o jovem atribuía significados próprios ao processo de adoecer. Apesar do sofrimento que o adoecimento por câncer acarretou em sua adolescência, esse período foi marcado pela determinação e coragem de viver sem sentir-se adoecido. Podemos exemplificar com os relatos apontando os afazeres que desenvolvia na propriedade rural familiar (Fig.1, 3CV $)$ :

[...] O meu pai ele mexe com leite, aí sempre, todo dia cedo, a gente levanta pra tirar leite [...] (Marco)

[...] e sentia bem. E ele tomava quimio antes de ontem, ontem, chegava hoje já ia pro curral! (Rita).

O jovem encontrava no trabalho do campo motivação que ultrapassava os limites impostos pelo adoecimento, proporcionando certa sustentação do seu equilíbrio emocional.

Ao longo desse período, Marco pode contar com a fé e a forte ligação com Deus para amenizar seu sofrimento, usando-a como alicerce e fonte de forças (Fig. 1, 3CV ${ }^{\mathrm{b}}$ ):

Sempre eu acreditava em Deus né... sempre tive fé [...] falava: com a fé em Deus, eu tenho fé que eu tô curado, [...] e não importava né, [...] eu nunca coloquei na cabeça que aquilo era um problema pra mim (Marco).

Porém, mesmo crente em sua fé e buscando manter algumas atividades cotidianas, cujo gerenciamento estava sob seu domínio, enfrentou outras dificuldades ocasionadas pelo câncer, dentre elas, o convívio social retraído e a reprovação escolar (Fig.1, 3CV', $3\left(V^{d}\right)$ :

Só que eu ia [referindo-se às festas] a doutora falava: "você pode ir! Você não fica no meio do povo". Aí sempre eu ficava afastado, mas nunca fui, assim, de ficar lá no meião lá... [...] Na escola eu também reprovei [...] teve uma época que eu perdi três anos de escola (Marco). 
Um ano e oito meses após o término do tratamento quimioterápico, o linfoma recidivou (Fig.1, 4A $\mathrm{A}^{\mathrm{d}}$ ) e Marco necessitou de novo tratamento, porém, com fármaco não fornecido pelo Sistema Único de Saúde (SUS) (Fig.1, 4A $\mathrm{A}^{\mathrm{e}}$. A família precisou empreender intensos esforços para conseguir o medicamento por via judicial (Fig.1, 3CV $C^{g}$ e, apesar da concessão da liminar judicial tardar um mês, o fornecimento do medicamento pelo poder público demorou seis meses.

Aos 20 anos, Marco foi encaminhado para uma clínica especializada em oncologia para ser acompanhado por um oncologista de adulto (Fig.1, 4A $\mathrm{A}^{\mathrm{a}}$ ). O linfoma pouco regrediu com o uso da medicação (Fig.1, $4 \mathrm{~A}^{\mathrm{b}}$ ) e Marco passou a realizar radioterapia, que reduziu consideravelmente a massa tumoral (Fig.1, 4A $\mathrm{A}^{\mathrm{c}}$. Essa fase do tratamento foi marcada por sofrimento devido à reação adversa, que causava danos à mucosa oral que o impediam de se alimentar (Fig.1, 4CV $)$.

No período de realização do trabalho de campo deste estudo, o jovem havia se mudado para a Cidade B (Fig.1, 4CV ), estava namorando e relatou a perspectiva e desejo de constituir família e estudar (Fig.1, 4CV ${ }^{\mathrm{d}}$ ). Também continuava o acompanhamento regular com o médico especialista em oncologia (Fig. $1,4 \mathrm{~A}^{\mathrm{d}}$ ), bem como do problema renal em Hospital Público de Cuiabá, estando em uso do medicamento citrato de potássio para a litíase renal que o acometia (Fig.1, 4A $\mathrm{A}^{\mathrm{e}}$.

\section{DISCUSSÃO E CONCLUSÃO}

Para elaborarmos a discussão de nossos resultados tomamos como parâmetro os documentos do Ministério da Saúde brasileiro (8, 14) que abordam o ciclo de vida do adolescente e o desenvolvimento da criança e adolescente, conforme expresso na Figura 1. Assim, trazendo a "normalidade esperada" exposta em tais documentos, daremos destaque ao modo como os agravos concomitantes, sinérgicos em seus afetamentos, ocasionaram o incremento de outras normalidades vivenciadas por Marco em sua infância e adolescência, também afirmadas por sua família.

$\mathrm{O}$ termo infância vem do latim infans e significa 'incapaz de falar'; compreende o período desde o nascimento até, aproximadamente, três anos de idade, quando a fala já se transformou em instrumento de comunicação (14). Nessa fase, muitos eventos ocorrem pela primeira vez: o primeiro sorriso, a primeira palavra, os primeiros passos, o primeiro alcançar de um objeto (Fig.1, 1Da).

A criança é um ser dinâmico, complexo e em constante transformação. Seu desenvolvimento apresenta sequência com certa previsibilidade e regularidade no crescimento físico (14). A capacidade de elaboração simbólica vai aumentando, gradativamente: inicia-se pelo choro, que a mãe entende como demanda; passa pelas fases do balbucio, dos gestos, das pequenas palavras, até a elaboração de frases e criação de suas próprias histórias (Fig. $1,1 D^{\mathrm{b}}$ ). A criança interage com o carinho da mãe e é capaz de demonstrar sinais de prazer (sorrir) e de desconforto (chorar ou resmungar) $(14)\left(1 \mathrm{D}^{c}\right)$.

O recém-nascido adquire o controle voluntário do choro após um mês de idade, manifestado com vários estados psicofisiológicos como fome, sofrimento e dor (15). Porém, em situação de adoecimento que exige tratamento hospitalar, outros significados são atribuídos ao choro, dado o enfrentamento da situação, pois, acrescendo-se ainda a necessidade de procedimento cirúrgico, a criança se sente fora do seu contexto, causando-lhe dor e estresse $(16,17)$.

Marco, no entanto, nasceu e cresceu envolto pelo sofrimento dos sintomas iniciais do agravo renal. Era uma criança chorosa e queixosa, sendo sua infância marcada por dores intensas, edemas e dificuldade de eliminações vesicais. E se, para uma criança é esperado que ela cresça e desenvolva de forma tranquila e saudável, na vida de Marco o adoecimento instaurou no seu cotidiano 
modos próprios de viver, nem sempre tão fáceis, mas perseverante, mesmo diante das agudizações dos sintomas e idas frequentes aos hospitais.

A infância é marcada pelo aprimoramento de habilidades, tais como, as capacidades de comunicação, locomoção, manuseio de objetos e jogos simbólicos, por meio do brincar e o explorar (Fig.1, 2D a $^{\mathrm{a}}$. Constitui-se, ainda, numa fase em que a criança começa a vivenciar sentimentos ambivalentes em relação aos mais próximos, especialmente, o pai e a mãe, chorando e fazendo birras diante de proibições (Fig.1, 2D ). É um período de relevância, uma vez que a criança está dando grandes passos em direção à independência (Fig.1, 2D ${ }^{c}$ ), experimentando-se como ser único (14).

Embora autores (2) afirmem que o estar "doente" provoca modificações intensas na vida da criança e família, particularmente se hospitalizada, podendo trazer prejuízo no desenvolvimento físico e mental. Contudo, Marco rememorou esse tempo como prazeroso. Brincava, fazia amizades e mantinha-se alegre, conforme esperado para uma criança. Mostrava-se, pois, consoante a autores que afirmam que a criança em adoecimento crônico tende a encarar a enfermidade como um fator externo, lidando com dificuldades devido ao sofrimento físico e as restrições das atividades; porém, isso não a impede de realizar tarefas que lhes são características (18).

E se não bastassem os rearranjos no cotidiano para lidar com o adoecer renal ao longo de toda infância, Marco e família ainda foram surpreendidos, no início da adolescência, pelo câncer, ampliando-lhes o sofrimento ao terem que lidar com seu estigma e tratamento, suscitando intensos desafios nesta fase da vida (19).

Conforme a Organização Mundial da Saúde (OMS), a adolescência compreende o período entre 10 e 19 anos e, além das modificações corporais oriundas da puberdade, ocorrem variadas alterações emocionais, dentre elas o desenvolvimento social e a bus- ca por identidade, vivenciada de forma peculiar por cada adolescente $(8,20)$. Consiste em uma fase dinâmica e complexa que perpassa a infância e a idade adulta e marca inúmeras modificações biológicas, psicológicas e sociais que repercutirão por toda vida (20), delineando uma identidade sexual, familiar e laboral, permitindo que o adolescente venha a exercer determinados papéis dentro da sociedade, sendo esta identidade sua imagem própria (Fig.1, 3Dª) (8).

A notícia do adoecimento por câncer para Marco, mais uma vez, foi ocasião para exercício da superação. Nos encontros de entrevista, mostrou que se mantinha confiante, não deixando a doença tomar conta de sua vida, tampouco da sua constituição biológica, mas sim, considerando-a como algo que brevemente deixaria de experienciar.

Autores afirmam que o adolescente, ao receber a notícia de uma doença crônica, em especial o câncer, procura como refúgio para seus medos e incertezas a não reflexão sobre a doença e tratamento, tomando a experiência como algo a ser vivido e não como algo complexo que valide passar por sua conscientização (21).

Embora guiasse sua vida com otimismo e confiança, o período da dinâmica terapêutica imposta pelo câncer foi o momento em que Marco sentiu o 'pesar' de encontrar-se adoecido, mediante os efeitos colaterais dos quimioterápicos: fraqueza, vômitos frequentes e, principalmente, a alopecia, que lhe causou mais intenso sofrimento. Esse significado especial em relação à perda dos cabelos pode estar relacionado à preocupação com o corpo, que se encontra em constantes transformações na adolescência (Fig.1, 3D ${ }^{c}$ ) (8). Quando o desenvolvimento do corpo é prejudicado ou insatisfatório, o impacto psicológico acarreta no adolescente sentimento de desvalorização e inferioridade, interferindo de maneira significativa em suas relações pessoais e afetivas (8).

$\mathrm{Na}$ adolescência, vivenciam-se intensos momentos de transição, necessidade de afir- 
mação e variados desajustes que contribuirão para a formação da identidade adulta (8). Fazem parte do transcorrer da adolescência: busca de si mesmo e de sua identidade; separação progressiva dos pais; tendência grupal; necessidade de intelectualizar e fantasiar; crises religiosas; deslocamento temporal; evolução da sexualidade; atitude social reivindicatória; entre outros (Fig.1, 3D b) (8).

Diante de tantas mudanças nessa fase da vida, o adoecimento crônico acarreta significativas repercussões físicas, psicológicas e sociais, duráveis durante todo o processo de adolescer. Estas causam grande impacto na vida da pessoa, culminando em estresse decorrente das limitações impostas pela enfermidade, interferências nas atividades cotidianas e nos projetos futuros, além da dificuldade de os adolescentes e suas famílias lidarem com a situação, já que não condiz com seu processo de crescimento e desenvolvimento $(8,22)$.

Tal condição se acentua quando há descompasso entre a lógica do cuidado familiar com a das práticas em saúde na esfera profissional, principalmente no que tange a carência de serviços de saúde que possam atender as intensas necessidades do adolescente e família que vivenciam o adoecimento, ampliando, sobremaneira, seu sofrimento. Neste contexto, concordamos que as limitações impostas pelos serviços guardam estreita relação com o estresse e o cansaço que se intensificam pela necessidade de dispêndio extra de energia pela família da pessoa adoecida diante dos inúmeros cuidados demandados (23). Em consonância com nossa percepção, estudo aponta a importância dos profissionais e serviços de saúde atuarem em prol da melhor assistência à saúde, considerando a biografia e a situação de vida de cada pessoa adoecida crônica (24).

Esta biografia conjuga-se com o viver em família, lugar de apoio e referência para aquele que vive e adoece. Marco nos conta a intensa e amorosa relação que o unia a seus familiares, de modo que todos se sentissem responsabilizados para lhe oferecer o melhor cuidado.

A notícia de um adoecimento crônico na família gera grande impacto em seu cotidiano, sendo as dificuldades do adolescente compartilhadas, de forma contundente, por seus pais e/ou responsáveis (8). Reforçamos, assim, que a família configura-se a base do ser humano, conformando-se em lugar de apoio mútuo, assumindo imprescindível importância àqueles que adoecem. $\mathrm{O}$ apoio familiar nessa peculiar situação de agravos concomitantes exigiu rearranjos e superações constantes na vida de Marco e sua família "permitindo-nos apreender os aspectos do viver em família e as dinâmicas que a regem no cuidado aos seus entes" (25).

Marco também recebeu importante ajuda da comunidade rural em que residia, cujos membros uniram seus esforços proporcionando ajuda financeira e espiritual ao longo do tratamento. Entendemos que a co-responsabilização e a troca de experiências entre as pessoas podem ajudar no desenvolvimento de estratégias para enfrentar as dificuldades do adoecimento e hospitalização, principalmente a do jovem em adoecimento (26).

Por ser uma fase em que o adolescente anseia por autonomia (Fig.1, 4D $\mathrm{D}^{\mathrm{a}}$ ), entendida como "autogoverno, auto determinação e implica no direito de o indivíduo tomar decisões sobre a saúde, relações sociais e, em última instância, sobre sua vida" (8), o adolescente, ao vivenciar o adoecimento crônico, pode não aceitar as limitações por ele impostas. Fato que não ocorreu com Marco, pois, apesar das orientações médicas para restringir algumas atividades, sempre buscava realiza-las de modo que não prejudicasse o tratamento (Fig.1, 3CVe). Ainda, apesar da magnitude das situações sofridas com o adoecer, sobressaia a força e a coragem de viver, inclusive, não mudando sua rotina de afazeres no trabalho na propriedade rural.

Sua forte ligação com Deus, por meio da fé, oferecia apoio emocional mediante os diversos acontecimentos. Concordamos com 
autores (27) ao salientarem que as estratégias de enfrentamento beneficiam, significativamente, o processo adaptativo do adoecer, reduzindo o estresse causado pela situação, conferindo sentido, estabilidade e conforto diante da doença. Assim, compreendemos que a espiritualidade constitui-se em uma dessas estratégias diante de situações consideradas difíceis, como foi o caso dos tratamentos oncológico e renal, permeados de sofrimento.

No entanto, apesar da sua força de vontade, fé e determinação, Marco também encontrava empecilhos por conta da manifestação dos sintomas e tratamento, como a interrupção na sua vida escolar e certo isolamento social. Na adolescência, a pessoa encontra na escola, além de um cenário de estudo, um ambiente favorável para o desenvolvimento das relações sociais, troca de experiências e maturidade (28). Entretanto, ao viver o adoecimento crônico, a escolarização do adolescente é interrompida ou dificultada devido a buscas por atendimento de suas necessidades em saúde, caracterizadas pelo excesso de consultas, exames e internações em horário escolar (8).

No que refere à construção social da vida do adolescente, surgem conflitos que moldam o ser: na adolescência média (14 a 17 anos) os embates que emergem dizem respeito à independência familiar e o início dos relacionamentos amorosos (Fig.1, $4 \mathrm{D}^{\mathrm{b}}$ ) (8); na fase tardia (17 a 20 anos) os principais problemas são relativos ao ingresso profissional, inquietações com o futuro, entre outros (8) (Fig.1, 4D $\mathrm{D}^{\mathrm{c}}$. Tais processos foram experienciados por Marco de modo indissociado do adoecer crônico, repercutindo em seu modo de andar a vida; entretanto, sempre buscava superar as limitações impostas pelo adoecimento, inclusive diante das recidivas ou agudizações dos agravos.

Autor salienta que, na adolescência, a pessoa é capaz de compreender e contribuir na tomada de decisão no seu cuidado, procurando maneiras mais efetivas para controlar os sintomas e ter domínio daquilo que seja melhor para seu bem-estar (29). Para tanto, é importante que a família e os profissionais de saúde o incluam nas decisões acerca do cuidado, concedendo-lhe oportunidades de realizar o próprio cuidado e, assim, tornar mais efetivo o enfrentamento positivo dessa vivência.

Embora o adoecimento por agravos concomitantes fizesse parte da vida de Marco desde sua infância, ele o vivenciava de maneira própria, ativa, otimista, reestruturando sua vida em favor de um futuro esperançoso, dele advindo a vontade de fazer um curso universitário.

Tendo aqui apresentado a descrição minuciosa da história de vida de Marco, na lógica de seu próprio relato assim como de seus familiares, os resultados do estudo se configuraram em uma forma mais narrativa. Entendemos que estudos de cunho descritivo, no bojo da compreensão de uma única experiência, podem apoiar a analise temporal de pessoas que vivem o adoecimento, permitindo identificar as trajetórias do adoecer e seus afetamentos no decorrer da vida (30).

Consideramos que o desenho da linha do adoecer em concomitância com o adolescer nos proporcionou apreender diferentes fases do desenvolvimento, considerando seu aspecto emocional, físico, comportamental e social; e também as implicações que o adoecimento crônico causou no jovem e família que, desde sua infância, buscam, produzem e gerenciam o cuidado a ele dispensado. Ressaltamos, também, que a permanência do adoecimento crônico continua a exigir do jovem e família a constante capacidade de se rearranjar, renovar e reconstruir seu modo de vida.

A direção metodológica descritivo-analítica, intencionalmente eleita por nós, embasada na experiência humana do adoecer, ainda mais intensamente vivida, ao se dar em concomitância com o adolescer, dá relevo aos contornos próprios e pessoalizados dessa situação. Essa compreensão nos faz reforçar a 
importância deste estudo como contribuição para o conhecimento em enfermagem, tanto na sua dimensão assistencial quanto da pesquisa, ao provocar reflexões acerca do viver, adolescer e adoecer, possibilitando instigar mudança nas práticas profissionais em saúde e enfermagem, de modo que sejam mais acolhedoras às necessidades ampliadas daqueles que vivenciam situação análoga, tornandose, então, mais efetivas em diminuir-lhes o sofrimento.

\section{REFERÊNCIAS}

1. Beresin R. Psicologia do desenvolvimento: O Adolescente. En: Farah OGD, Sá AC. Psicologia aplicada à enfermagem. Barueri: Manole; 2008. 175 p.

2. Schneider CM, Medeiros LG. Criança hospitalizada e o impacto emocional gerado nos pais. Rev. Unoesc \& Ciência ACHS. 2011; 2(2): 140-154.

3. Martins CBG, Alencastro LCS, Matos KF, Almeida FMA, Souza SPS, Ferreira SC. As questões de gênero quanto à sexualidade dos adolescentes. Adolesc Saude. 2012; 9(1): 25-32.

4. Araujo YB, Collet N, Gomes IP, Nobrega RD. Enfrentamento do adolescente em condição crônica: importância da rede social. Rev Bras Enferm [Internet]. 2011 Mar-Abr [citado 26 maio 2014]; 64(2): 281-6. Disponível em: http://www.scielo. br/pdf/reben/v64n2/a10v64n2.pdf

5. Almeida IS, Rodrigues BMRD, Simões SMF. Artigo de reflexão: hospitalização do adolescente. Rev. Soc. Bras. Enferm. Ped [Internet]. 2007 Jul [citado 4 setembro 2014]; 7(1): 33-9. Disponível em: http://www.sobep.org.br/revista/images/ stories/pdf-revista/vol7-n1/v.7_n.1-art4. refl-hospitalizacao-do-adolescente.pdf

6. Ayres JRCM. Organização das ações de atenção à saúde: modelos e práticas. Saúde Soc. 2009; 18 Suppl 2: 11-22.
7. Leal DT, Fialho FA, Dias IMAV, Nascimento L, Arruda WC. A vivência dos familiares de crianças e adolescentes portadores de Diabetes mellitus tipo 1. Rev. Eletr. Enf. [Internet]. 2012 Jan-Mar [citado 4 setembro 2014]; 14(1): 189-196. Disponível em: http://www.fen.ufg.br/ fen_revista/v14/n1/pdf/v14n1a22.pdf.

8. Ministério da Saúde (BR). Saúde do adolescente: competências e habilidades [Internet]. Brasília: Secretaria de Atenção à Saúde, Departamento de Ações Programáticas Estratégicas; 2008 [citado 4 setembro 2014]. 753 p. Série B. Textos Básicos da Saúde. Disponível em: https:// www.ufpe.br/medicina/images/Textos_ recomendados/saude_adolescente_competencias_habilidades_2008.pdf

9. Dolina JV, Bellato R, Araújo LFS. O adoecer e morrer de mulher jovem com câncer de mama. Cien Saude Colet [Internet]. 2013 Set [citado 4 setembro 2014]; 18(9): 2671-2680. Disponível em: http://www.scielo. $\mathrm{br} / \mathrm{scielo}$.php? script $=$ sci_arttext\&pi$\mathrm{d}=\mathrm{S} 1413=81232013000900022$-\&lngen. http://dx.doi.org/10.1590/S141381232013000900022.

10. Musquim CA, Araújo LFS, Bellato R, Dolina JV. Genograma e ecomapa: desenhando itinerários terapêuticos de família em condição crônica. Rev. Eletr. Enf. [Internet]. $2013 \mathrm{Jul} / \mathrm{Set}$ [citado 30 agosto 2014]; 15(3): 656-666. Disponível em: http://www.revenf.bvs.br/pdf/ree/ v15n3/07.pdf

11. World Health Organization (WHO). Relatório Mundial de Saúde 2008: Cuidados de saúde primários, Agora mais que nunca. Switzerland: WHO; 2008. 130 p.

12. Bellato R, Araújo LFS. For a comprehensive approach of family care experience. Rev. Cienc Cuid Saude. 2015; 14(3): 1394-1400.

13. Araújo LF, Dolina J, Petean E, Musquim CA, Bellato R, Lucietto GC. Diário de pesquisa e suas potencialidades na pes- 
quisa qualitativa em saúde. Rev. Bras. Pes. Saúde. 2013; 15(3): 53-61.

14. Ministério da Saúde (BR). Saúde da criança: crescimento e desenvolvimento [Internet]. Brasília: Secretaria de Atenção à Saúde, Departamento de Atenção Básica; 2012 [citado 4 setembro 2014]. 272 p. Cadernos de Atenção Básica No 33. Disponível em: https://mooc.campusvirtualsp.org/repository/coursefilearea/file. php/27/zika_es/res/u3/caderno_33.pdf

15. Branco A, Fekete SMW, Rugolo LMSS, Rehder MI. Valor e variações da frequência fundamental no choro de dor de recém-nascidos. Rev. CEFAC [Internet]. 2006 Out-Dez [4 setembro 2014]; 8(4): 529-35. Disponível em: http://www.scielo.br/pdf/rcefac/v8n4/v8n4a14.pdf.

16. Martins STF, Paduan VC. A equipe de saúde como mediadora no desenvolvimento psicossocial da criança hospitalizada. Rev. Psicol. Estud. [Internet]. 2010 [citado 10 maio 2014]. 15(1): 45-54. Disponível em: http://www.scielo.br/pdf/pe/ v15n1/a06v15n1.pdf.

17. Coronel MK. Cirurgia Pediátrica: benefícios do acompanhamento psicológico. Rev. Perspect. 2011; 35(132): 81-92.

18. Melo LL, Valle ERM. A Brinquedoteca como possibilidade para desvelar o cotidiano da criança com câncer em tratamento ambulatorial. Rev Esc Enferm USP [Internet]. 2010 Jun [citado 10 maio 2014]; 44(2): 517-525. Disponível em: http://www.scielo. $\mathrm{br} /$ scielo.php? script $=$ sci_arttext $\&$ pi$\mathrm{d}=\mathrm{S} 0080=62342010000200039-\& \ln \mathrm{-}-$ en. http://dx.doi.org/10.1590/S008062342010000200039.

19. Till T. Coping with câncer: the adolescent experience. Australian. [Masters thesis]. [Victoria]: Australian Catholic University; 2004. 145 p.

20. Moraes SP, Vitalle MSS. Direitos sexuais e reprodutivos na adolescência. Rev Asso Med Bras. [Internet]. 2012 [citado 5 junho 2014]; 58(1): 48-52. Disponível em: http://www.scielo.br/pdf/ramb/v58n1/ v58n1a14.pdf

21. Ângelo M, Cunha MLR, Moreira PL, Gomes S. Adolescentes com câncer: necessidades de informações. Rev. Soc. Bras. Enferm. Ped. [Internet]. 2011 Dez [citado 4 setembro 2014]; 11(2): 93-100. Disponível em: http://sobep.org.br/revista/images/stories/pdf-revista/vol11-n2/v.11_n. 2-art4.adolescentes-com-cancer.pdf

22. Araújo YB, Collet N, Gomes IP, Amador DD. Saberes e experiências de adolescentes hospitalizados com doença crônica. Rev. enferm. UERJ [Internet]. 2011 AbrJun [citado 4 setembro 2014]; 19(2): 2749. Disponível em: http://www.facenf.uerj. br/v19n2/v19n2a17.pdf

23. Hiller M, Bellato R, Araújo LFS. Cuidado familiar à idosa em condição crônica por sofrimento psíquico. Esc. Anna Nery [Internet]. 2011 Set [citado 4 setembro 2014]; 15(3): 542-549. Disponível em: http://www.scielo. $\mathrm{br} / \mathrm{scielo}$.php?script=sci_arttext\&pi$\mathrm{d}=$ S1414=81452011000300015-\&lngen. http://dx.doi.org/10.1590/S141481452011000300015.

24. Kalitzkusa V, Matthiessenb PF. Personal growth in chronic illness - a biographical case study of living with fibromyalgia. Forsch Komplementmed. 2010; 17(4): 203-208.

25. Almeida, KBB, Araújo LFS, Bellato R. Family caregiving in chronic illness: a young person's experience. REME. 2014; 18(3): 724-32.

26. Silva MAS, Collet N, Silva KL, Moura FM. Cotidiano da família no enfrentamento da condição crônica na infância. Acta Paul Enferm [Internet]. 2010 [citado 5 junho 2014]; 23(3): 359-65. Disponível em: http://www.scielo.br/pdf/ape/v23n3/ v23n3a08.pdf.

27. Iamin SRS, Zagonel IPS. Estratégias de enfrentamento (coping) do adolescente com câncer. Psicol. Argum. 2011; 29(67): 427-435. 
28. Machado de Oliveira D, Fulgencio LP. Contribuições para o estudo da adolescência sob a ótica de Winnicott para a Educação. Psicol. Rev. 2010; 16(1): 67-80. 29. Callaghan EE. Achieving Balance: A Case Study Examination of an Adolescent Co- ping With Life-Limiting Cancer. J Pediatr Oncol Nurs. 2007; 24(6): 334-339.

30. Linder LA. Developmental Diversity in Symptom Research Involving Children and Adolescents with Cancer. J Pediatric Nurs. 2008; 23(4): 296-309. 